\title{
A new genus and species of troglobitic Trechinae (Coleoptera, Carabidae) from southern China
}

\author{
Augusto Vigna Taglianti *
}

\section{SUMMARY}

Guizhaphaenops zorzini n.gen.n.sp. is described from Anjia Yan Cave, Shuicheng County, Guizhou (China). This highly specialized troglobite species is easily recognizable from the other cave dwelling Trechini from China for the main morphological external characters, but its true relationships remain uncertain, the male being still unknown. Similar in habitus to Cathaiaphaenops and to Sinotroglodytes, the new taxon is much more related to the latter, being dorsally glabrous and having the mentum fused with the submentum, with a deep oval fovea, but it differs in its elongated head, with incomplete frontal furrows and without posterior frontal setae.

Only few years ago an extraordinary new genus and species, Sinaphaenops mirabilissimus Ueno \& Wang, 1991, was discovered in Guizhou (Libo County), in Southeast China; it was the first record of an anophthalmic trechine beetle from mainland China (Ueno \& Wang, 1991). None of the eyeless trechine species, quite abundant in the temperate zones, especially in Northern Hemisphere and also in Eastern Asia, with many genera and species described from Taiwan, Korea and especially Japan (see also Vigna Taglianti \& Casale, 1996), was previously known from China. Another new genus and species, Dongodytes fowleri Deuve, 1993, was described two years later from Guangxi, collected by an expedition organized by Chinese and British speleologists.

Recently, in a paper by Deuve (1996), three other anophthalmic cavedwelling trechines were described from Northwest Hunan, collected in the karst of Longshan in August 1995, by French and Chinese speleologists of the expedition "Xiangxi 95"; they were ascribed to two new genera (Cathaiaphaenops and Sinotroglodytes) and to one new subgenus (Cimmeritodes) of the Japanese genus Gotoblemus Ueno, 1970.

One year before, in August 1994, also "China Caves '94", the third speleological Italian expedition to China (Zorzin \& Melotti, 1995; see also Vigna Taglianti, 1995, for the "Sichuan '93 Project"), visited some karstic areas in Guangxi and Guizhou provinces. This expedition was organized by dr Roberto

* Dipartimento di Biologia Animale e dell'Uomo (Zoologia), Università di Roma "La Sapienza”, Viale dell'Università, 32 - I 00185 Roma, Italy. 
Zorzin, geologist at the Museo Civico di Storia Naturale di Verona, Department of Geology and Paleontology (for the scientific aspects), and dr Silvano Melotti, of the Centro Ricerche Naturalistiche Monti Lessini, Verona (for the speleological aspects), and carried out in cooperation with the Guizhou Normal University. Among the few zoological samples collected in Chinese caves, and given to prof. Sandro Ruffo, former Director of the Museo Civico di Storia Naturale di Verona, for sorting and studying, there was also one carabid beetle, that was subsequently kindly and friendly forwarded to me. This specimen belongs to a new genus and species of highly specialized eyeless Trechinae, whose description is the object of the present note.

\section{Guizhaphaenops n.gen.}

\section{Diagnosis}

An highly specialized, but not aphaenopsoid, trechine genus, with very elongated antennae and legs, round pronotum and large ovate elytra, with serrulate shoulders. Similar to the genus Sinotroglodytes Deuve, 1996, in the general shape of the body and appendages, and in having the mentum fused with submentum, with a deep oval fovea, the new taxon clearly differs in elongated head, with incomplete frontal furrows, and without posterior frontal setae, in the right mandible strongly bidentate, in the labial tooth clearly bifid, in the outer prebasilar setae longer and stronger, in the presence of the posterior lateral setae on pronotum, in the clearly keeled protibiae and in the pubescent ventral surface.

Known only on a female specimen, the true relationships of the new genus are still uncertain, the male remaining unknown.

\section{Type species}

Guizhaphaenops zorzini Vigna Taglianti, n.sp.

\section{Description}

A trechine genus, showing a high morphological adaptive modification to the cave environment. Medium sized, with very elongated antennae and legs, round pronotum and large ovate elytra (Fig. 1); surface completely glabrous on dorsum, except the thiny pubescent genae, but well pubescent on abdominal sternites. Inner wings totally reduced. Colour reddish brown, relucent and shiny.

Head elongated, longer than prothorax, narrow, with a clear neck constriction; frontal furrows incomplete, divergent and obsolete posteriorly; eyes completely vanished; genae parallel, with very short, thin and sparse hairs; only one 


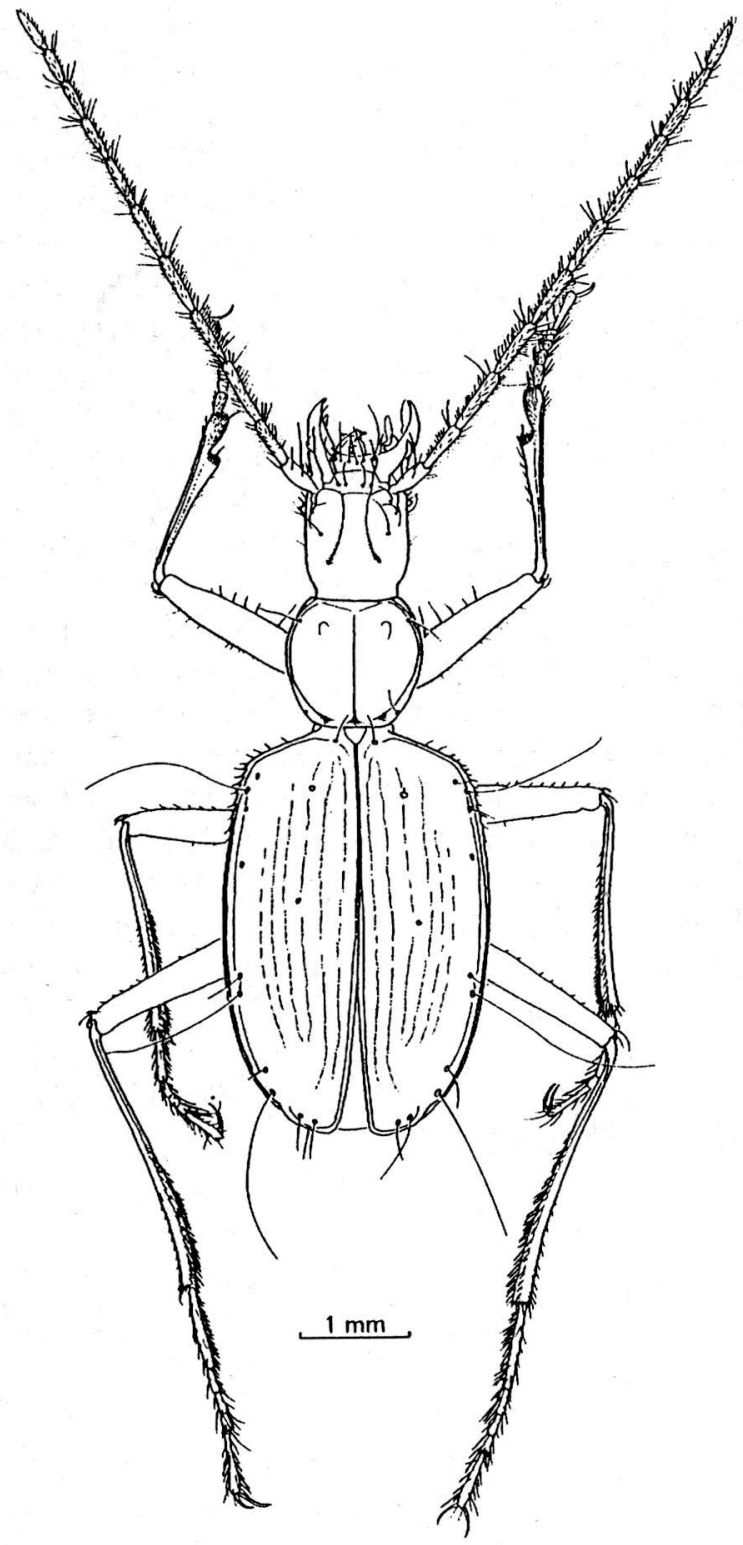

Fig. 1 - Guizhaphaenops zorzini n.gen. n.sp., from Anjia Yan cave in Guizhou, holotype: habitus.

pair of frontal setae (the anterior ones), behind the level of ocular oblique sutura; two pairs of short setae above the antennal base; clypeus with right margin, 
and with four setae, the outers being much longer and stronger; labrum gently emarginate at the apex, with six setae, the outers much longer, the inner ones very short and thin. Mandibles slender, feebly arcuate, acute at apices; the right mandible strongly bidentate (Fig. 2), the left one with straight cutting edge. Labium (Fig. 3) completely fused, without trace of labial suture; mentum with a porrect tooth in apical emargination, half as long as lateral lobes, bifide at the tip; in the middle, the mentum shows a depressed round-oval fovea, deep, behind the apical setae (two, lined with the deeper emarginations) and before the semicircular series of nine prebasilar setae. Of these setae, the inner (five, at the apex of submentum) and the apical ones (two, at the basal sides of mentum) are similar in length and size, the outer (at the side angles of submentum) are much more longer and stronger. Ligula triangularly produced, octosetose (the apical two setae are longer and stronger); paraglossae moderately arcuate, extending much beyond the ligula; labial palpus long and slender, penultimate segment slightly curved and dilated at the apex, with two setae at the apex and one, longer, at half the length, on the anterior side; apical segment about four-fifths as long as the penultimate. Maxillae slender, with lacinia gently curved and provided with recurved spines and hairs on the inner margin; maxillary palpus (Fig. 3) long and slender, glabrous, with only three short setae at the apex of penultimate segment; penultimate segment long, subcylindrical in the basal half and sinuately dilated towards the apex; apical segment about eight-ninths as long as the penultimate. Antennae long and slender, reaching the four-fifths of the elytral length; scape is the thickest of all segments, and the less setose, while the penultimate is the shortest and segment 3 the longest.

Prothorax short; pronotum round-ovate, as long as head (without labrum) and slightly wider than long, with the maximum width at the half of the lenght; sides gently arcuate, more gradually narrowing towards the base than towards the apex; front angles obtusely rounded, hind angles completely rounded, continuous with the base; lateral fine borders continuing onto apex and base, gently and gradually enlarged behind the basal third; basal foveae indistinct, superficial, extending anteriorly with the side borders. Marginal setae present, the apical one being the longest; the apical ones situated before the first-fifth of the length, the basal ones at the posterior tenth, before the hind angle. Scutellum distinct.

Elytra ovate, much wider than prothorax, with maximum width at basal third, gently narrowing towards the apex; slighly convex, with flattened basal and humeral area; oblique prehumeral borders, distinct shoulders, narrowly rounded apices; side borders complete from basal peduncle to apex, serrulate at shoulders, with short setae at the apex of each denticulation (10-12, in the basal fourth); striae shallow, vanishing at the sides, at the base and at the apex; the inner four striae more complete and deeper; basal pore present; two setiferous 
dorsal pores present on stria 3 , the anterior one before the fore sixth, the posterior one clearly before the middle; preapical pore absent; two apical pores present, slightly internal to the recurrent stria; marginal series of umbilicate pores not aggregate, as in Fig. 1: the first pore a little distant from marginal gutter, the second (at the level of the fore discal pore) adjoining the marginal gutter, the third a little distant from gutter, like the first one; all three anterior pores very close to each other, equidistant; the fourth widely distant (three time the distance between the previous), displaced from the gutter; fifth and sixth also very close to each other, the sixth adjoining the gutter; seventh and eighth at a similar distance to each other, at the apical sixth of elytron, the eighth adjoining marginal gutter.

Ventral surface with sternites 4-7 bearing a relatively thick and long pubescence; 4-6 with one pair of median setae along the posterior margin; in female, sternite 7 with two pair of similar setae, the outer being a little longer than inner ones.

Legs very long and slender; fore legs with clearly sulcate tibiae, with thick apical pubescence on inner side; tibiae of median and hind legs thiny sulcate on the entire inner side, with pubescence on inner face, thicker towards the apices; tarsi slender, pubescent on dorsal side.

Female genital appendages (Figs 4-5) without peculiar features; penultimate segment of gonostyli with two subapical spines on dorsal surface; apical segment elongate, gently curved, with two dorsal (inner and outer) spines and ventral sensorial fovea, with two thin hairs.

\section{Derivatio nominis}

The generic name is composed by "Guizhou" (the Province toponym) and "aphaenops", to recall the name of the classic, specialized, speciose and widespread genus of cave-dwelling Trechini, Aphaenops, meaning "without visible eyes".

\section{Guizhaphaenops zorzini n.sp.}

\section{Diagnosis}

A medium sized trechine, included in Guizhaphaenops n. gen., with elongated head, neck constriction clearly visible, shortened frontal furrows, frontal posterior seta lacking, right mandible strongly bidentate, labial tooth clearly bifid, outer prebasilar setae longer and stronger, hind lateral setae of pronotum present, clearly keeled protibiae and pubescent ventral surface. 

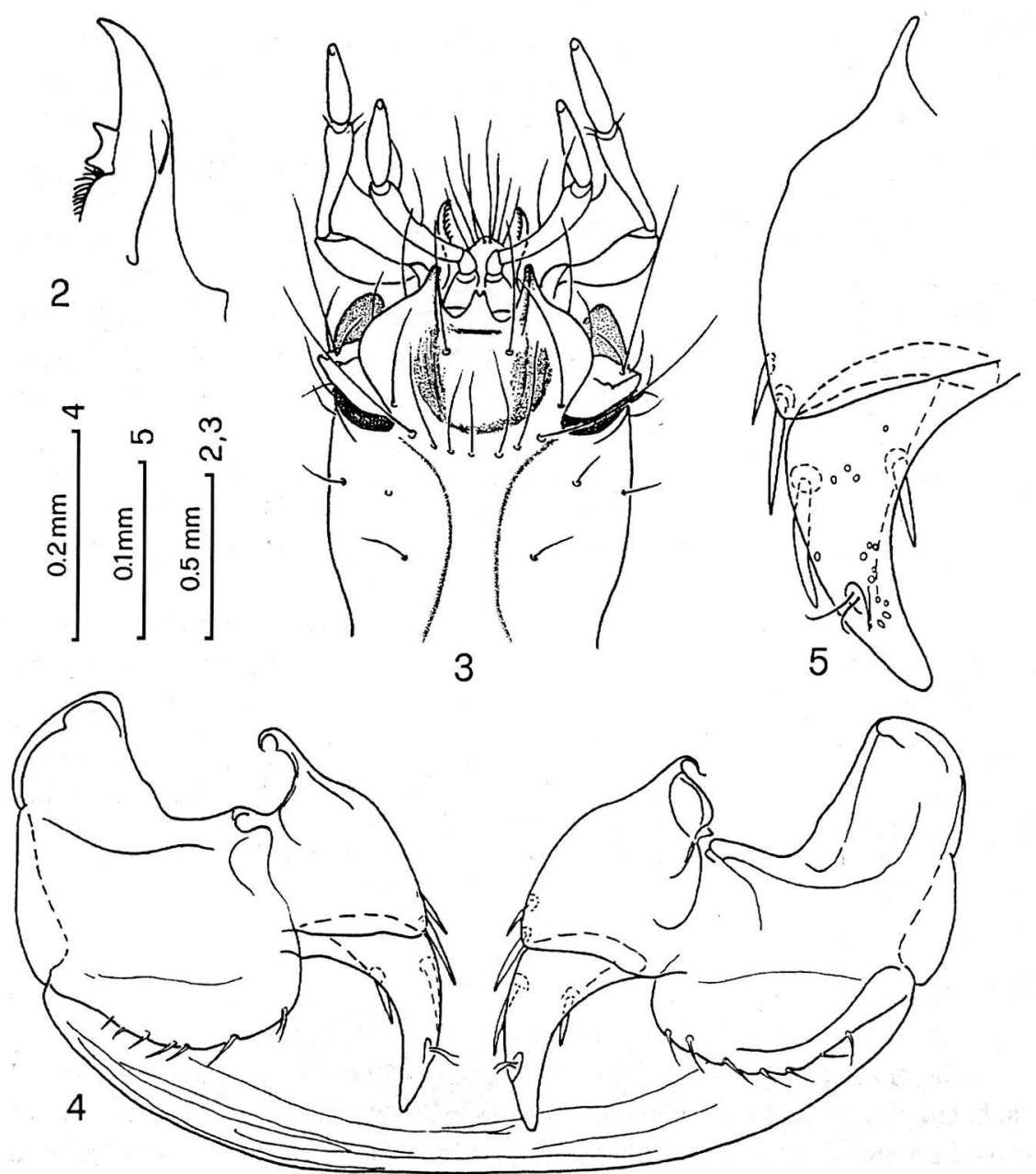

Figs 2-5 - Guizhaphaenops zorzini $\mathrm{n}$.gen. n.sp., holotype: right mandible (2), labium and maxillary palpi (3), genital appendages (4) and left gonostylus, at major magnification (5).

\section{Type material}

Holotype: female, China, Guizhou Province, Suicheng County, Show Ga, Anjia Yan cave, 20.VIII.1994, R. Zorzin leg., in Coll. Vigna Taglianti, at the Zoological Museum of "La Sapienza" University, Rome. 


\section{Description}

Complete description as for the genus.

Total length $6.12 \mathrm{~mm}$ from apical margin of clypeus to apices of elytra.

Head a little longer than wide: length (from apical margin of clypeus to apical margin of pronotum) $1.25 \mathrm{~mm}$, greatest width (behind level of the frontal setae) $0.9 \mathrm{~mm}$. Antennae $5.1 \mathrm{~mm}$ long. Microsculpture reticulate, in fine polygonal meshes.

Pronotum round-oval; length (along the mid-line) $1.18 \mathrm{~mm}$, greatest width (at mid length) $1.18 \mathrm{~mm}$. Microsculpture reticulate, with fine meshes transversely stretched.

Elytra ovate, narrowing towards apices; greatest length $3.67 \mathrm{~mm}$, greatest width (behind level of the 4 marginal umbilicate pore) $2.24 \mathrm{~mm}$. Microsculture clearly transverse.

Legs slender, elongated; length of hind tibia $2.55 \mathrm{~mm}$.

\section{Derivatio nominis}

It is a pleasure to dedicate this new species, the sixth specialized cave dwelling trechine so far known from China, to its collector, dr Roberto Zorzin, a good friend of the author and organizer of the "China Caves '94" Italian speleological expedition.

\section{Ecological notes}

The type locality, Anjia Yan cave, whose name is from a nearby little village in the Shuicheng County (Guizhou, China), lies in the locality Show Ga, about $50 \mathrm{~km}$ northwestwards from Shuicheng, $2160 \mathrm{~m}$ above sea level.

This cave, open inside limestone aged between Devonian and Triassic, of fossil type, with only few pools with dropping water, is about $300 \mathrm{~m}$ long, with $65 \mathrm{~m}$ of difference in heigth from entrance to the end. The cave is shortly described by Zorzin \& Melotti (1995), and the map and section were made by the "China Caves '94" expedition (not yet published). The cave has a wide entrance, lenghtened orizontally, with an enormous rock slab above large masses of slides. The voult develops sub-horizontally and has a rather regular configuration, while the floor is covered by slide masses. Many concretions are present, occasionally very large. A narrow meander (7-8 $\mathrm{m}$ deep on average, at some points $20 \mathrm{~m}$ deep) runs along the entire length, with pools of dropping water on the bed.

The cave, from the ecological point of view, is of the temperate type: the temperature of the air into the cave was $10.8^{\circ} \mathrm{C}$ (outdoor $18.6^{\circ} \mathrm{C}$ ), of the water $10.6^{\circ} \mathrm{C}$. 